\title{
Modelling tracer transport by a cumulus ensemble: lateral boundary conditions and large-scale ascent
}

\author{
M. Salzmann ${ }^{1}$, M. G. Lawrence ${ }^{1}$, V. T. J. Phillips ${ }^{2}$, and L. J. Donner ${ }^{2}$ \\ ${ }^{1}$ Max-Planck-Institute for Chemistry, Department of Atmospheric Chemistry, PO Box 3060, 55020 Mainz, Germany \\ ${ }^{2}$ Geophysical Fluid Dynamics Laboratory, NOAA, Princeton University, PO Box 308, Princeton, NJ 08542, USA
}

Received: 10 May 2004 - Published in Atmos. Chem. Phys. Discuss.: 22 June 2004

Revised: 31 August 2004 - Accepted: 3 September 2004 - Published: 13 September 2004

\begin{abstract}
The vertical transport of tracers by a cumulus ensemble at the TOGA-COARE site is modelled during a 7 day episode using 2-D and 3-D cloud-resolving setups of the Weather Research and Forecast (WRF) model. Lateral boundary conditions (LBC) for tracers, water vapour, and wind are specified and the horizontal advection of trace gases across the lateral domain boundaries is considered. Furthermore, the vertical advection of trace gases by the largescale motion (short: vertical large-scale advection of tracers, VLSAT) is considered. It is shown that including VLSAT partially compensates the calculated net downward transport from the middle and upper troposphere (UT) due to the mass balancing mesoscale subsidence induced by deep convection. Depending on whether the VLSAT term is added or not, modelled domain averaged vertical tracer profiles can differ significantly. Differences between a 2-D and a 3-D model run were mainly attributed to an increase in horizontal advection across the lateral domain boundaries due to the meridional wind component not considered in the 2-D setup.
\end{abstract}

\section{Introduction}

Deep convective clouds can rapidly transport trace gases from the lower troposphere to the upper troposphere (e.g. Gidel, 1983; Chatfield and Crutzen, 1984; Dickerson et al., 1987; Pickering et al., 1990) where in many cases their chemical lifetimes are longer and horizontal winds often are stronger. On the other hand, tracers are transported downwards due to the mass balancing mesoscale subsidence induced by deep cumulus clouds and due to downdrafts inside deep convective clouds. Both upwards as well as downwards transport have been found to influence global budgets of im-

Correspondence to: M. Salzmann

(salzmann@mpch-mainz.mpg.de) portant trace gases such as ozone (Lelieveld and Crutzen, 1994; Lawrence et al., 2003).

In recent years cloud-resolving models (CRMs) have been used by numerous investigators to study the transport of tracers (e.g. Scala et al., 1990; Wang and Chang, 1993; Andronache et al., 1999; Skamarock et al., 2000; Wang and Prinn, 2000; Pickering et al., 2001; Ekman et al., 2004). In each of these studies the evolution of a single deep convective storm was simulated. Lu et al. (2000) presented the first multi-day 2-D model study of trace gas transport by a cumulus ensemble. They applied periodic lateral boundary conditions (PLBC) and observed large-scale advection (LSA) terms for water vapour and potential temperature, but neglected the corresponding terms for tracers. Particularly in situations with vertical wind shear, model calculated tracer fields obtained with PLBCs will not necessarily be meaningful if the model is run longer than the time $\tau_{a d v}=L / \bar{v}_{\text {max }}$ it takes the tracer to be advected across the entire length of the domain and the tracer's chemical lifetime is longer than or comparable to $\tau_{a d v}$. Here $\bar{v}_{\max }=\max (\bar{v}(z))$ is the maximum domain averaged horizontal wind speed, and $L$ is the horizontal domain length. On the other hand if LBCs for trace gases and for the wind are specified, the horizontal wind is allowed to change the vertical tracer gradients and thus the vertical transport. In this study a framework is presented which enables investigators to drive cloud-resolving chemistry transport models with observed data for longer periods taking into account large-scale influences that in previous CRM transport studies were neglected. In this approach water vapour, tracer concentrations and wind components are specified at the lateral boundaries of the domain, while for other variables PLBCs are applied. Furthermore a VLSAT term is included. Chatfield and Crutzen (1984) noted in their early study of cloud transport that the influence of the synoptic-scale circulation should be described in order for the air chemistry results to be credible. In contrast to their study, in the approach presented here we do not 
attempt to model the large-scale circulation, but instead incorporate its influence in the CRM by specifying LBCs for tracers and adding a VLSAT term. Pickering et al. (1990) considered horizontal tracer advection in a one-dimensional photochemical model in order to achieve agreement between modeled and observed profiles of nitrogen monoxide and carbon monoxide. In their study, the term representing horizontal advection was independent of the horizontal wind. Here it will be argued that large scale influences also have to be considered in multi-day CRM studies of tracer transport. In Sect. 2 the model and the model setup are described focusing on the treatment of LBCs and the VLSAT in this study. The results of sensitivity studies with different model setups for modelled meteorology and tracer transport are presented in Sects. 3 and 4. An extended discussion of the results and the method follows in Sect. 5.

\section{Model description and model setup}

\subsection{Model description}

A modified height coordinate prototype version of the nonhydrostatic, compressible Weather and Research and Forecast Model (WRF) is used in this study. The WRF model is a community model which is being developed in a collaborative effort by the National Center for Atmospheric Research (NCAR), the National Centers for Environmental Prediction (NCEP), the Air Force Weather Agency, Oklahoma Univesity and other university scientists. It was designed as a regional model which is capable of operating at high resolutions. The source code as well as additional information can be obtained from the WRF model web site at http://wrf-model.org. The basic equations can be found in Skamarock et al. (2001) and the numerics are described in Wicker and Skamarock (2002). Microphysical processes are parameterized using a single-moment scheme (Lin et al., 1983) which is not part of the WRF model distribution. The scheme is described by Krueger et al. (1995) and is based on a study by Lord et al. (1984). The mass mixing ratios of water vapour, cloud water, rain, cloud ice, graupel, snow and tracers are transported using the Walcek (2000) monotonic advection scheme instead of the third order RungeKutta scheme which is currently implemented in the WRF model prototype. The third order Runge-Kutta scheme is used to solve the momentum equations and the theta equation using fifth/third order spatial discretizations for horizon$\mathrm{tal} / \mathrm{vertical}$ advection terms. Shortwave radiation is parameterized using the Goddard shortwave scheme (Chou et al., 1998) and for parameterizing longwave radiation the RRTM scheme (Mlawer et al., 1997) is used in the simulations. Subgrid scale turbulence is parameterized applying Smagorinsky's closure scheme (e.g. Takemi and Rotunno, 2003).

\subsection{Large-scale advection}

Tropical deep convection tends to occur under conditions of large-scale low level convergence and tropospheric ascent, e.g. in the rising branch of the Hadley or the Walker circulation which cannot be reproduced by a limited area CRM with the domain sizes computationally affordable today. In many studies large-scale advection (also referred to as largescale forcing or advective forcing) tendencies for the water vapour mixing ratio $q$ and the potential temperature $\theta$ based on observations are added to the right hand side of the prognostic CRM equations and the model is run in the so-called semi-prognostic manner first introduced by Soong and Ogura (1980). The LSA tendencies can be expressed as:

$$
\begin{aligned}
& \left(\frac{\partial \bar{\theta}}{\partial t}\right)_{L S}=-\overline{\boldsymbol{v}} \cdot \nabla \bar{\theta}-\bar{w} \frac{\partial \bar{\theta}}{\partial z} \\
& \left(\frac{\partial \bar{q}}{\partial t}\right)_{L S}=-k \overline{\boldsymbol{v}} \cdot \nabla \bar{q}-\bar{w} \frac{\partial \bar{q}}{\partial z}
\end{aligned}
$$

where overbars denote horizontal domain averaged values and $k=1$ when PLBCs for $q$ are used and $k=0$ (no horizontal LSA of $q$ ) whenever LBCs for $q$ are prescribed. Instead of prescribing the large-scale advection entirely from observed values it is also possible to calculate the second term on the right hand side from observed values $\bar{w}_{o b s}$ together with model calculated values of $\bar{q}$ and $\bar{\theta}$ as done by Soong and Ogura (1980). Sensitivity studies testing both methods yielded sufficiently similar results for the purpose of this study, and we decided to use the aforementioned method of prescribing the entire right hand sides of Eqs. (1) and (2) from observations (see Fig. 1) based on data from Ciesielski et al. (2003). In addition to prescribing the LSA terms, Soong and Ogura (1980) retained the products of domain averaged and perturbation variables in their model, while in many other studies (e.g. Xu et al., 1992; Johnson et al., 2002) these terms were neglected. Here $q$ and $\theta$ were specified entirely based on observations and these products were also neglected. For $q$ and $\theta$, perturbations are usually small relative to their base (horizontally averaged) values, while e.g. for a trace gas with a surface source and a low tropospheric background concentration this is not the case when the upwards transport of the trace gas in deep convective clouds sets in. For tracers a method of including large-scale transport is used which was previously used for $q$ and $\theta$ (Xu and Randall, 1996; Xu and Krueger, 1991). The vertical advection of these tracers due to the large-scale vertical velocity $\bar{w}_{o b s}$ is calculated, thus allowing horizontal inhomogeneity of the VLSAT. If the LBCs for tracers and wind are prescribed and the average horizontal wind components are nudged towards observed values, only the vertical advection due to $\bar{w}_{\text {obs }}$ must be considered and the VLSAT term is calculated from:

$$
\left(\frac{\partial \mu}{\partial t}\right)_{L S}=-\bar{w}_{o b s} \frac{\partial \mu}{\partial z}
$$



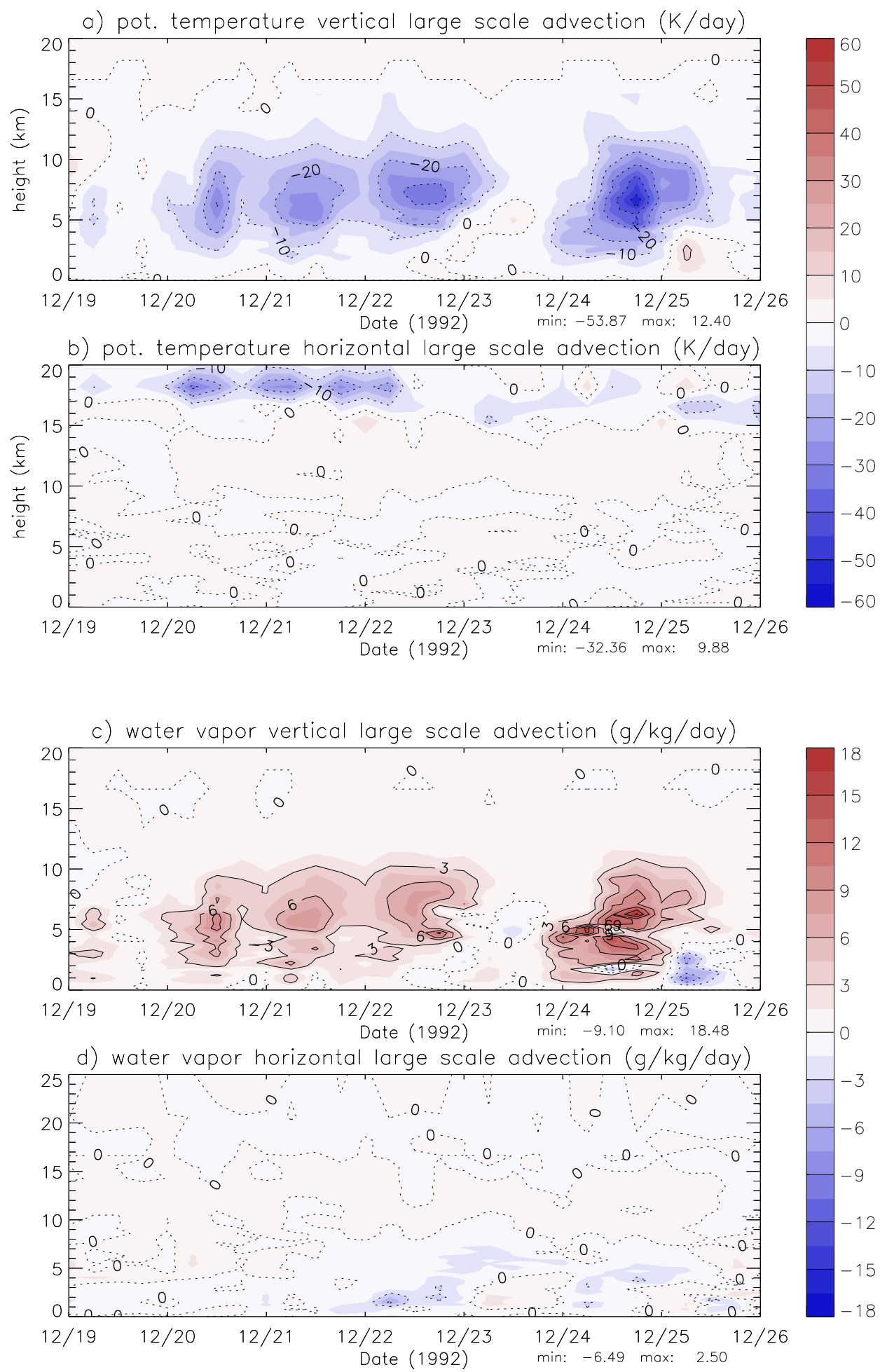

Fig. 1. Time-height contour plots showing observed vertical and horizontal large-scale advection tendencies of potential temperature and water vapour mixing ratio. Times are given in UTC. 
where $\mu$ is the modelled tracer mixing ratio and $\bar{w}_{o b s}$ is depicted in Fig. 2c. If $\bar{\mu}$ were inserted in Eq. (3) instead of $\mu$ the tracer advection by $\bar{w}_{o b s}$ would be non-local and the tracer would be spuriously dispersed across the entire model domain. In addition it would become necessary to apply a non-local scaling of the values in order to ensure positive definiteness and mass conservation simultaneously. In simulations of chemically reactive trace gases this would often cause significant problems. The average horizontal wind is nudged towards observed values (see Fig. 2):

$$
\left(\frac{\partial \overline{\boldsymbol{v}}}{\partial t}\right)_{L S}=-\frac{\overline{\boldsymbol{v}}-\overline{\boldsymbol{v}}_{o b s}}{\tau_{a d j}}
$$

where $\boldsymbol{v}=(u, v)$, as in e.g. Xu and Randall (1996) and Johnson et al. (2002) with an adjustment time $\tau_{a d j}=1 \mathrm{~h}$.

\subsection{Lateral boundary conditions}

In semi-prognostic model studies of deep convection PLBCs are used and LSA terms for water vapour and potential temperature are prescribed providing a means of simulating observed events. With PLBCs no fluxes into the model domain from the outside are allowed and the domain averaged net upward transport of air is zero. While for $q$ and $\theta$ the horizontal LSA terms (see Fig. 1b and d) can be small compared to the vertical LSA terms (in Fig. 1a and c), this can not be expected to be the case for moderately long lived trace gases, as will be demonstrated in this study. Thus, if no horizontal LSA terms for tracers are prescribed in multi-day studies of trace gas transport, PLBCs should not be used for tracers with lifetimes longer than those discussed above. Therefore, we decided to retain PLBCs for the potential temperature and the air density but specify LBCs for tracers and for water vapour. In this approach, periodic boundary conditions are also retained for the horizontal wind components, but $u$ and $v$ are nudged towards their observed values with extremely short adjustment times (twice the model timestep $d t$ ) at the lateral boundaries. Consequently, the LBCs for $u$ and $v$ can be considered prescribed LBCs. The vertical velocity $w$ and the concentrations of all hydrometeors in the liquid and the ice phase are set to zero at the lateral boundaries. The values for $q$ and the tracer concentration (partial density $\mu \rho$ ) at the lateral boundaries are specified in a zone which was chosen to be 2 grid points wide. For $u, v$ and $w$ this width is set to three points and additionally a four point wide relaxation zone is used in which the adjustment time increases linearly in order to avoid the generation of spurious waves. The microphysics scheme is not applied in an eight-pointswide boundary zone in order to avoid spurious condensation. This boundary zone is not considered in the analysis of the model results and not included in the domain lengths cited below. With the choice of LBCs presented here, tracers and water vapour are transported smoothly into the domain at the upstream lateral boundary. At the outflow boundary the same boundary condition was applied. If a higher or- der advection scheme were used, spurious upwind transport would in principle be possible and a more sophisticated outflow boundary condition may become necessary. In the runs using specified lateral boundary conditions for water vapour, time-dependent water vapour boundary values were specified based on observation-derived data from the Ciesielski et al. (2003) dataset.

\subsection{Simulation of the TOGA-COARE case}

A seven day period from 19-26 December 1992 at the site of the TOGA COARE (Webster and Lukas, 1992) Intensive Flux Array (IFA, centered at $2^{\circ} \mathrm{S}, 156^{\circ} \mathrm{E}$ ) is modelled which overlaps with the period chosen by the GEWEX Cloud System Study (GCSS Science Team, 1993) Working Group 4 as the 2nd case of their first cloud-resolving model intercomparison project (Krueger and Lazarus, 1999) and was also investigated by Wu et al. (1998), Andronache et al. (1999), Su et al. (1999), Johnson et al. (2002) and used in a model comparison by Gregory and Guichard (2001). During this period the IFA region is influenced by the onset of a westerly wind burst (see Fig. 2a) and three consecutive convection maxima develop between 20 and 23 December and a fourth and strongest maximum with its peak on 24 December at the times of maximum large-scale ascent (Fig. 2c) and vertical $q$ and $\theta$ LSA (Fig. 1a and c). The WRF-model as described in Sect. 2.1 is run with $2 \mathrm{~km}$ horizontal resolution and $350 \mathrm{~m}$ vertical resolution up to $19 \mathrm{~km}$ and decreasing resolution up to the model top at nearly $24.7 \mathrm{~km}$ with a total of 63 grid points in the vertical direction. The timestep is $5 \mathrm{~s}$ and small time varying random contributions (in the range $\pm 0.01 \mathrm{~g} / \mathrm{kg}$ for 2-D runs and $\pm 0.0125 \mathrm{~g} / \mathrm{kg}$ for the 3-D run) are added to the water vapour mixing ratio in the sub-cloud layer during the first $2.5 \mathrm{~h}$ of the simulation. Ten tracers with horizontally and vertically constant initial concentrations in $1750 \mathrm{~m}$ thick horizontal layers are included in the model runs. For three of these tracers a detailed analysis of the model results will be presented in the following. The tracers are assumed to be chemically inert, insoluble and to have no surface or tropospheric sources or sinks in the domain. At the lateral boundaries, the tracer concentrations are assumed to be constant and equal to their initial concentrations.

\subsection{Sensitivity studies}

The results from three 2-D runs, using a domain length of $500 \mathrm{~km}$ are discussed in detail. These three runs were performed in order to study the sensitivity towards different LBC and towards applying VLSAT. In the first run PLBCs are used. In the second run the water vapour, the concentrations of the hydrometeors in the liquid and the ice phase and the wind are specified at the lateral boundaries as described in Sect. 2.3. The tracer concentrations prescribed at the lateral boundaries are kept constant and are set equal to the initial tracer mixing ratios. For brevity, runs with specified tracer 

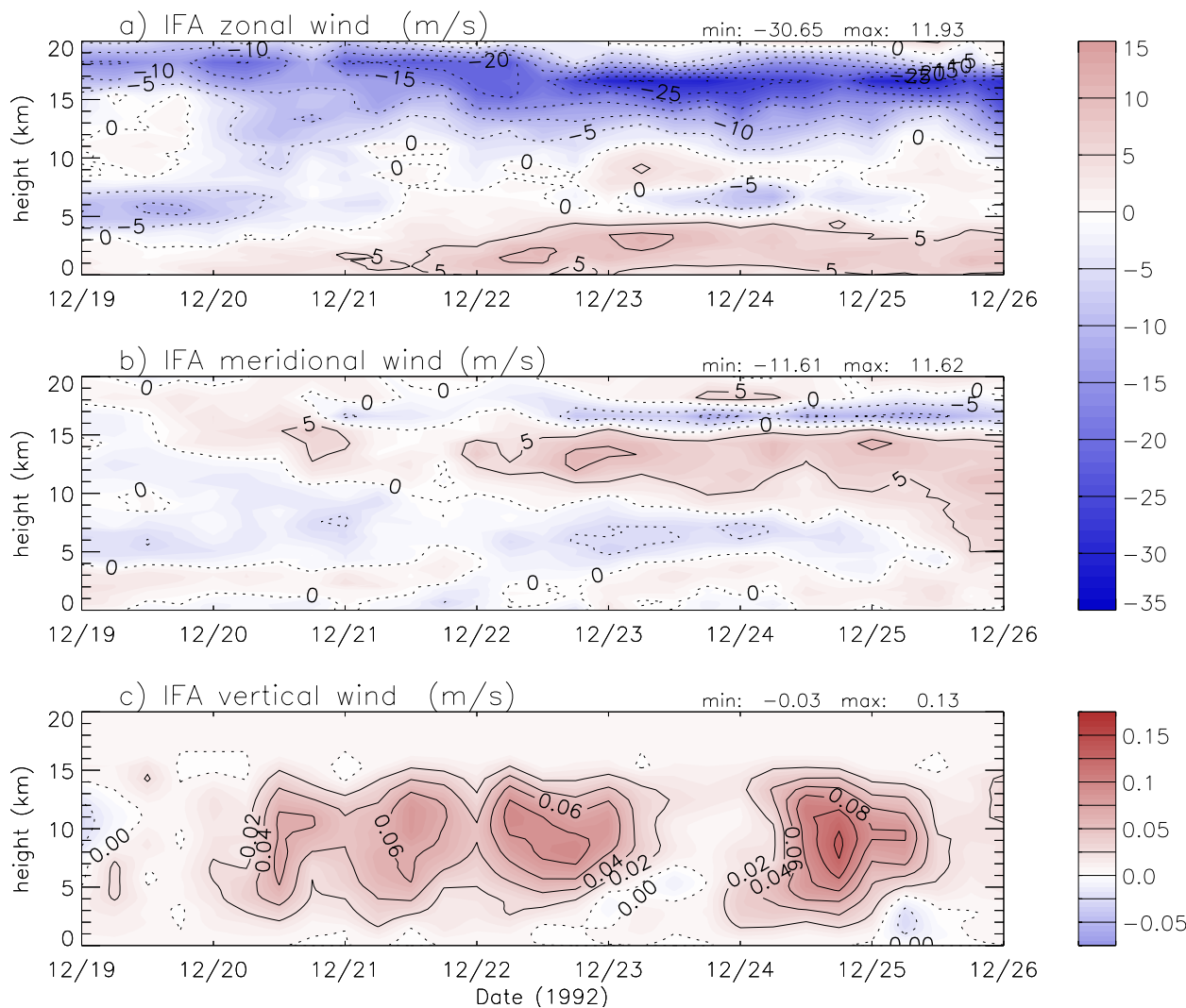

Fig. 2. Time-height contour plots of observed (a) zonal (b) meridional and (c) vertical wind components.

Table 1. Sensitivity runs, for abbreviations see text.

\begin{tabular}{lcr}
\hline Setup & Boundary Conditions & Large Scale Advection \\
\hline & 2-D sensitivity runs & \\
\hline 2-D $(500 \mathrm{~km})$ & PLBC & horiz. and vert. $q, \theta$ \\
2-D $(500 \mathrm{~km})$ & SLBC & vert. $q, \theta$ \\
2-D $(500 \mathrm{~km})$ & SLBC & vert. $q$, $\theta$, and TLSA \\
\hline & 3-D vs. 2-D sensitivity runs \\
\hline 2-D $(248 \mathrm{~km})$ & SLBC & vert. $q, \theta$, and TLSA \\
3-D $(248 \mathrm{~km} \times 248 \mathrm{~km})$ & SLBC & vert. $q, \theta$, and TLSA \\
\hline & additional sensitivity runs & \\
\hline 2-D $(1000 \mathrm{~km})$ & SLBC & vert. $q, \theta$, and TLSA \\
2-D $(500 \mathrm{~km})$, WRF Lin-scheme & SLBC & vert. $q, \theta$, and TLSA \\
\hline
\end{tabular}

and water vapour boundary conditions subsequently will be referred to as specified lateral boundary condition (SLBC) runs. In the third run the LBCs (and the calculated meteorology) are the same as in the second run, but additionally a VLSAT term (Eq. 3) is added when solving the tracers' continuity equations. In order to study the dependence of the model results on the domain size, two additional model runs using domain lengths of $248 \mathrm{~km}$ and $1000 \mathrm{~km}$ were performed. The results from these runs are mentioned occasionally and are not discussed in detail here. Except for the difference in domain size, the setup of these runs was identical to the setup of the third $500 \mathrm{~km}$ domain run, i.e. SLBCs were used and the VLSAT was considered. In Sect. 3, results from an additional 2-D run are mentioned. The setup 


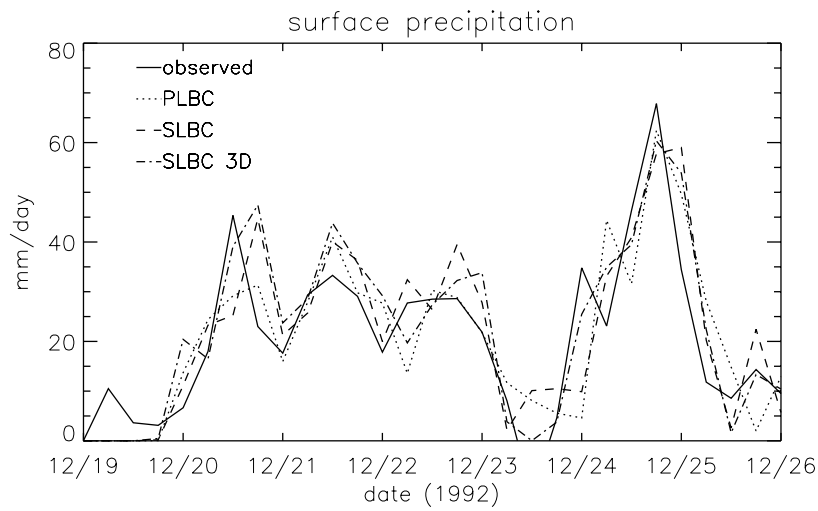

Fig. 3. Time series of observed and modelled $6 \mathrm{~h}$ averaged surface precipitation rates for PLBCs and for specified water vapour and wind LBCs.

of this run was identical to the third $500 \mathrm{~km}$ domain length run, but instead of the single-moment microphysics scheme described in Sect. 2.1, the Lin-scheme implemented in the standard WRF model was used. In addition to the 2-D runs described above, a 3-D run was performed. In this run, again SLBCs were applied and the TLSA was considered. The same vertical grid configuration was used as in the 2-D runs and the horizontal domain size was $248 \mathrm{~km} \times 248 \mathrm{~km}$. The results of the 3-D run are compared to results from the $248 \mathrm{~km}$ 2 -D run. An overview over the different setups used in the sensitivity runs is presented in Table 1 .

\section{Modelled meteorology}

The model computed precipitation rates generally compare well with the observed data (see Fig. 3). The total observed amount of rain for the seven day period from 19-26 December 1992 is calculated from the Ciesielski et al. (2003) data to be $149.1 \mathrm{~mm}$ and the simulated amount is $152.2 \mathrm{~mm}$ for the run with PLBCs. In SLBC runs the values are $162.6 \mathrm{~mm}$ for the 2-D and $171.8 \mathrm{~mm}$ for the 3-D run and thus somewhat higher than the observed value. On the other hand in a comparable 2-D run also using SLBCs but the Lin-scheme from WRF instead of the one described in Sect. 2.1, the computed value is $143.7 \mathrm{~mm}$ and is thus somewhat lower than the observed value (not shown in the figure). In general, with PLBCs a large over- or underestimation is unlikely to occur in a semi-prognostic setup since the computed amount of surface precipitation is largely constrained by the input data for the water vapour LSA. In contrast, with SLBCs the domain averaged horizontal flux divergence for water vapour at a given height level is determined by the model and is allowed to deviate from the measured values of the horizontal LSA, thus more easily allowing either an over- or an underestimation of the surface precipitation.
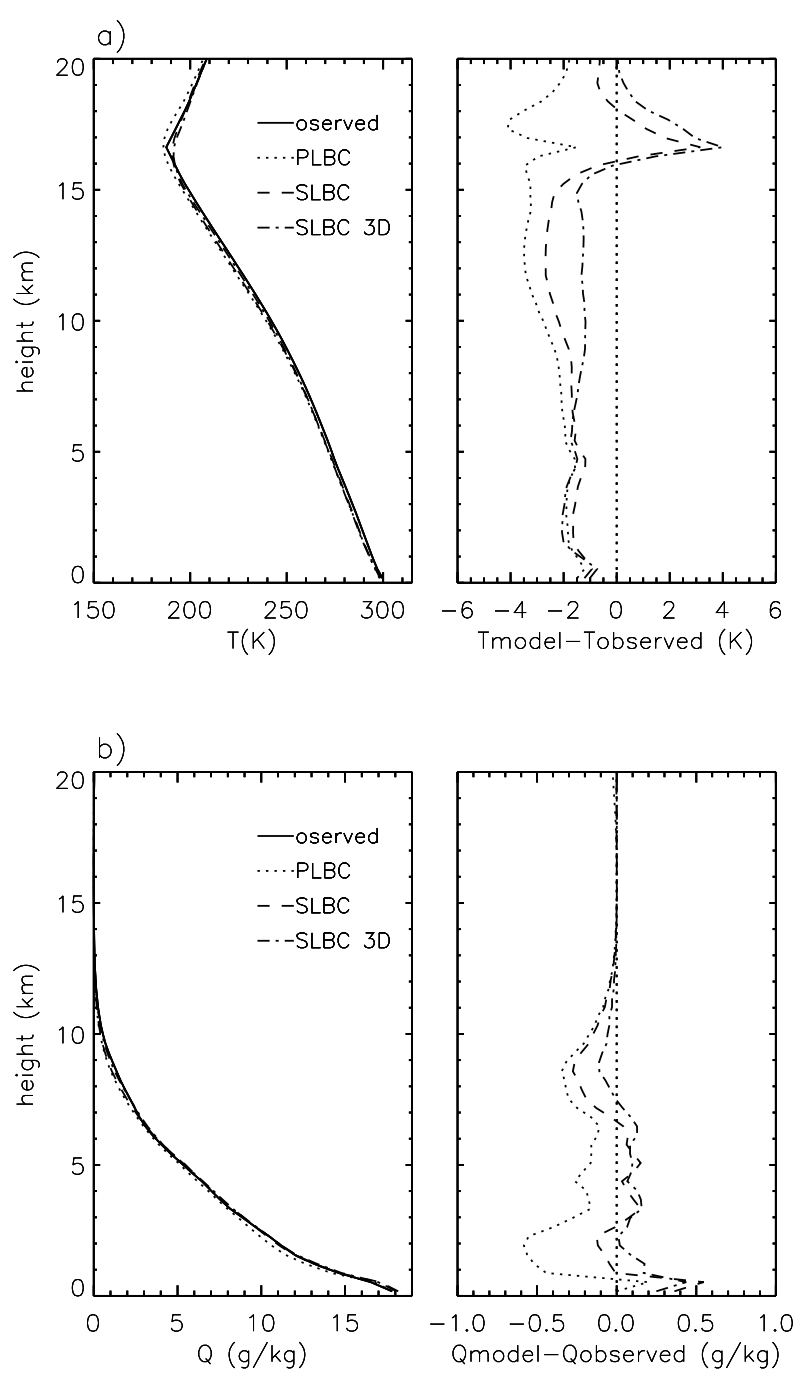

Fig. 4. Vertical profiles of observed and modelled domain and time averaged temperatures and water vapour mixing ratios.

Figure 4 depicts the differences between model calculated and observed average temperatures and water vapour mixing ratios. The cold temperature bias in the model runs in the troposphere is comparable to the bias in the 2-D-CRM study of Johnson et al. (2002) and for the 3-D run to the bias in the 3-D CRM model study of Su et al. (1999). The cold bias was e.g. discussed by Johnson et al. (2002). The different $\mathrm{q}$ biases in the SLBC runs compared to the PLBC runs are a consequence of the horizontal transport of water vapour into the domain, and of the differences in total precipitation discussed above.

For the $500 \mathrm{~km}$ domain 2-D runs the Hovmöller diagrams in Fig. 5a and $\mathrm{b}$ show squall lines propagating westwards at moderate speeds of mostly $\sim 3 \mathrm{~m} / \mathrm{s}$ (low propagation speed implies a steep slope in the diagrams) and faster eastwards moving single clouds (thin "lines" in the diagrams) for both PLBCs and SLBCs. 
a) PLBC

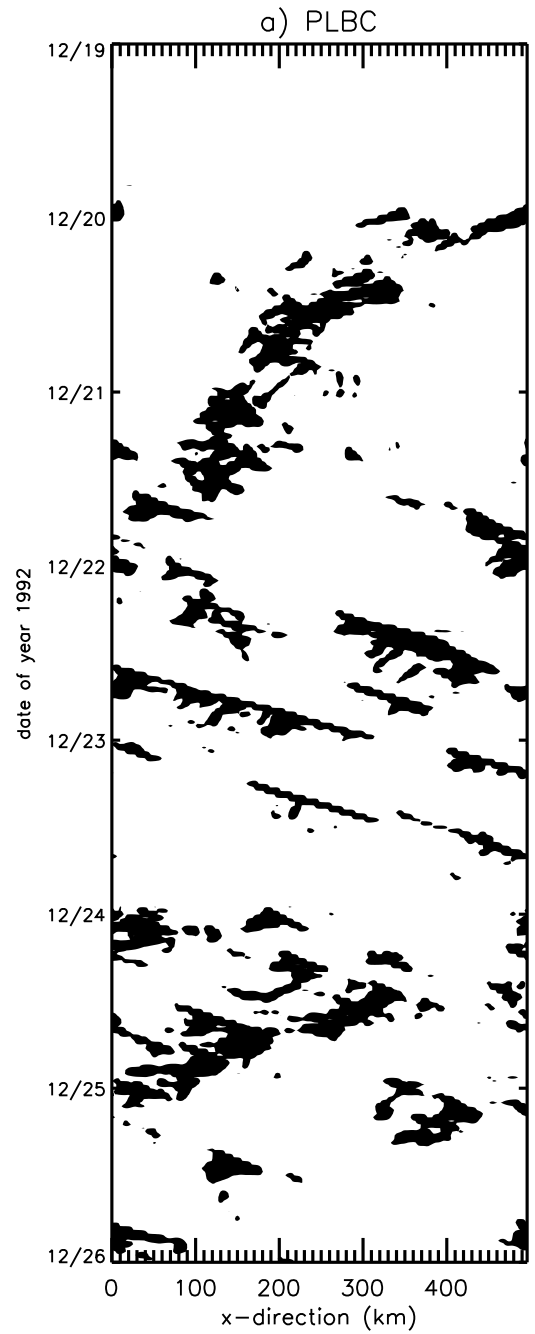

b) SLBC

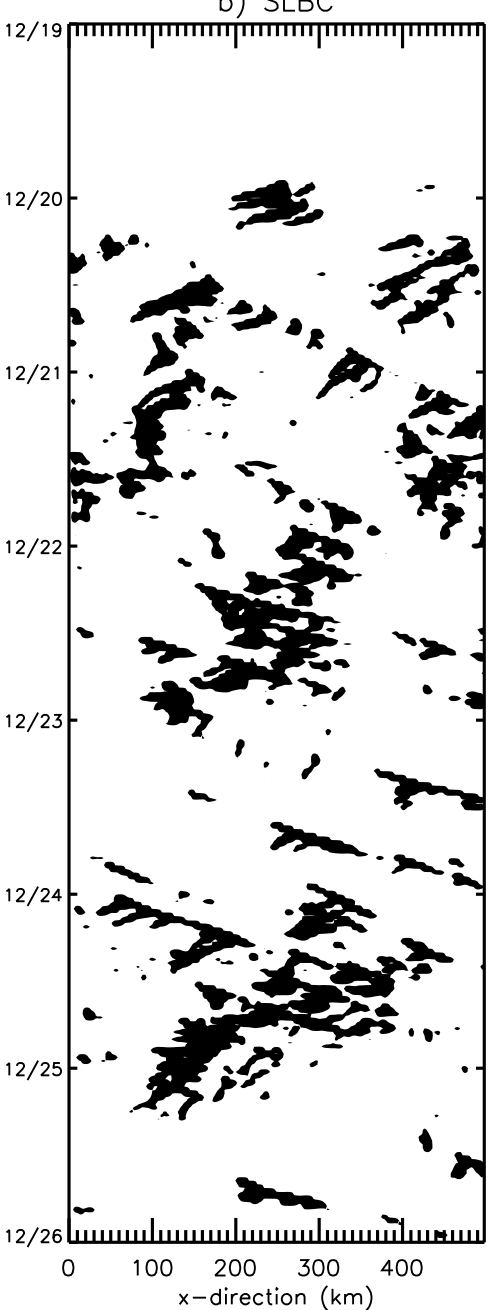

c) $\mathrm{SLBC} 248 \mathrm{~km}$

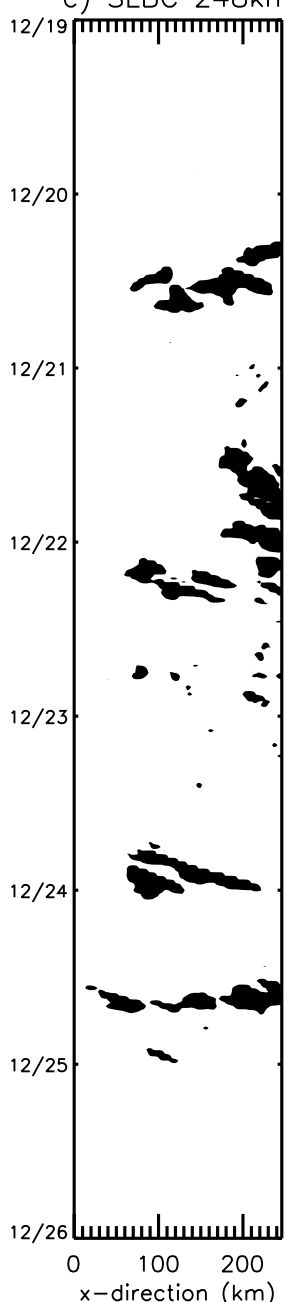

Fig. 5. Hovmöller diagrams: $1 \mathrm{~mm} / \mathrm{h}$ contour of model computed rainfall rates for (a) PLBCs and (b) specified water vapour and wind LBCs. (c): Same as (b) but for $248 \mathrm{~km}$ long domain.

Perhaps the most striking differences between the two sensitivity runs occur between 20 December and 23 December. In the run with PLBCs a single large squall line develops during the first two days of strong deep convective activity and during the next two days mostly single clouds and small squall lines dominate. In the SLBC run during the entire period, single clouds co-exist with large squall lines occurring during the latter half of the first four days of strong deep convective activity. In Fig. 5c a Hovmöller diagram for the $248 \mathrm{~km}$ domain 2-D run which will be utilized for the 2-D vs. 3-D tracer transport comparisons in the next section is shown. In this run the largest squall lines have smaller horizontal extents and shorter lifetimes than in the larger domain run.

\section{Modelled tracer transport}

The transport of the ten tracers included in the sensitivity runs was analysed using different methods. For the purpose of describing the main characteristics, it was found to be useful to choose three tracers for a detailed discussion. Subsequently these tracers will be referred to as tracer A, B and C. Tracer A was initialized in a lower tropospheric layer, tracer $\mathrm{B}$ in the mid-troposphere, and tracer $\mathrm{C}$ in the UT.

\subsection{Tracer A in 2-D runs}

\subsubsection{Periodic lateral boundary conditions}

Tracer A was initialized at a horizontally and vertically constant concentration in a lower tropospheric layer between 0 and $1750 \mathrm{~m}$ height. The time height contour plot of horizontally averaged modelled tracer mixing ratios (see Fig. 6a) shows the effect of rapid upward transport immediately after 


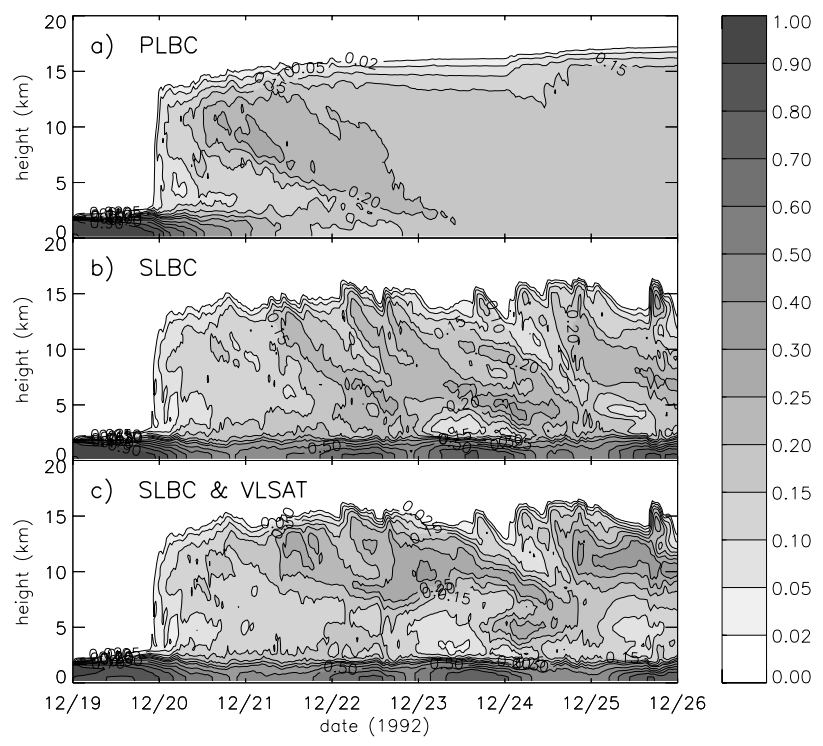

Fig. 6. 2-D sensitivity runs: Time-height contour plots of domain averaged tracer mixing ratios for tracer A initialized at a horizontally and vertically constant concentration in a layer between 0 and $1750 \mathrm{~m}$ altitude. The mixing ratio values plotted in this figure are normalized to the maximum initial mixing ratio. (a) Periodic lateral boundary conditions, (b) specified water vapour and wind lateral boundary conditions, (c) specified lateral boundary conditions and vertical large scale advection for tracers. Contour levels are: 0.0 , $0.02,0.05,0.1,0.15,0.2,0.25,0.3,0.4,0.5,0.6,0.7,0.8,0.9$. and 1.0 .

the onset of modelled deep convection at $\sim 23$ UTC on 19 December. Within the next day the amount of tracer in the boundary layer decreases rapidly, while in the UT a local maximum of the tracer mixing ratio forms (at the height of the cloud anvils). The altitude of this maximum starts decreasing immediately because of tracer mass descending due to the mass balancing mesoscale subsidence induced by the deep convection. Furthermore the mixing ratio of the tracer close to the surface is sufficiently depleted so that air advected rapidly upwards would not contain high enough tracer mixing ratios to account for the formation of further UT mixing ratio maxima. Later the vertical mixing is increased since some of the descending tracer is re-entrained into deep convective clouds and transported upwards. Four days after the onset of deep convection the tracer is well mixed throughout the model troposphere.

\subsubsection{Specified lateral boundary conditions}

As previously mentioned specifying LBCs for tracer allows for tracer advection across the model's lateral boundaries and the total amount of tracer inside the domain to be influenced by the mean horizontal wind. Like in the case of PLBCs tracer mass is rapidly transported from the lower troposphere (LT) to the UT when deep convection sets in (see
Fig. 6b). Initially the LT mixing ratio decreases as in the case of PLBCs. But between 21 December and 22 December the westerly wind burst sets in and wind speeds in the LT increase (see Fig. 2a). Tracer mass transported away from the LT inside the updrafts of the deep convective clouds is replenished by tracer mass horizontally advected into the model domain. Around the same time the wind increases in the UT and tracer mass is continously advected out of the domain across the lateral boundaries. The amount of tracer advected into the domain in the LT and the amount of tracers advected out of the domain at UT levels could be quantitatively assessed calculating the time-integrated horizontal and vertical advection tendencies. Integrated over longer episodes, the tendencies of horizontal and vertical advection at each vertical level approximately balance. As for the run with PLBCs (Fig. 6a), UT mixing ratio maxima with contours sloping towards the Earth's surface indicate the strong effect of mesoscale subsidence. When the VLSAT term is taken into account (see Fig. 6c) this effect of the mesoscale subsidence is also visible particularly at the time of the maximum in convective activity on 24 December, but once injected into the UT, the tracer mass often remains there for considerably longer times. For tracer A domain averaged vertical profiles are plotted in Fig. 7 reflecting the differences between the results of the different sensitivity runs discussed here. Significant differences between the SLBC run and the run with PLBCs already become apparent in Fig. 7b (less than $24 \mathrm{~h}$ after the onset of deep convection in the model). The profiles in Fig. 7 will be discussed in more detail in Sect. 5.

\subsection{Tracer B in 2-D runs}

\subsubsection{Periodic lateral boundary conditions}

Tracer B (see Fig. 8a) was initialized at a constant concentration in a layer between 7000 and $8750 \mathrm{~m}$ height and is chosen as a representative mid-tropospheric tracer. At the onset of deep convection this tracer is less effectively transported upwards since the levels of maximum entrainment of deep convective clouds are located in the lower troposphere (LT). The amount of tracer B in the UT increases much less rapidly than that of tracer A (compare Fig. 8a to Fig. 6a), because tracer $\mathrm{B}$ is less efficiently entrained into deep convective cells than tracer A. The finding that tracer B is entrained less efficiently than tracer $\mathrm{A}$ and that tracer $\mathrm{A}$ is predominantly detrained in the UT provides a different perspective than the "convective ladder" effect postulated by Mari et al. (2000). Tracer B is also transported downwards due to the mesoscale subsidence and after two days of active deep convection a substantial part of it has reached the LT from where it is then rapidly transported upwards. At the end of the studied period this tracer is still not homogeneously distributed throughout the entire troposphere. 

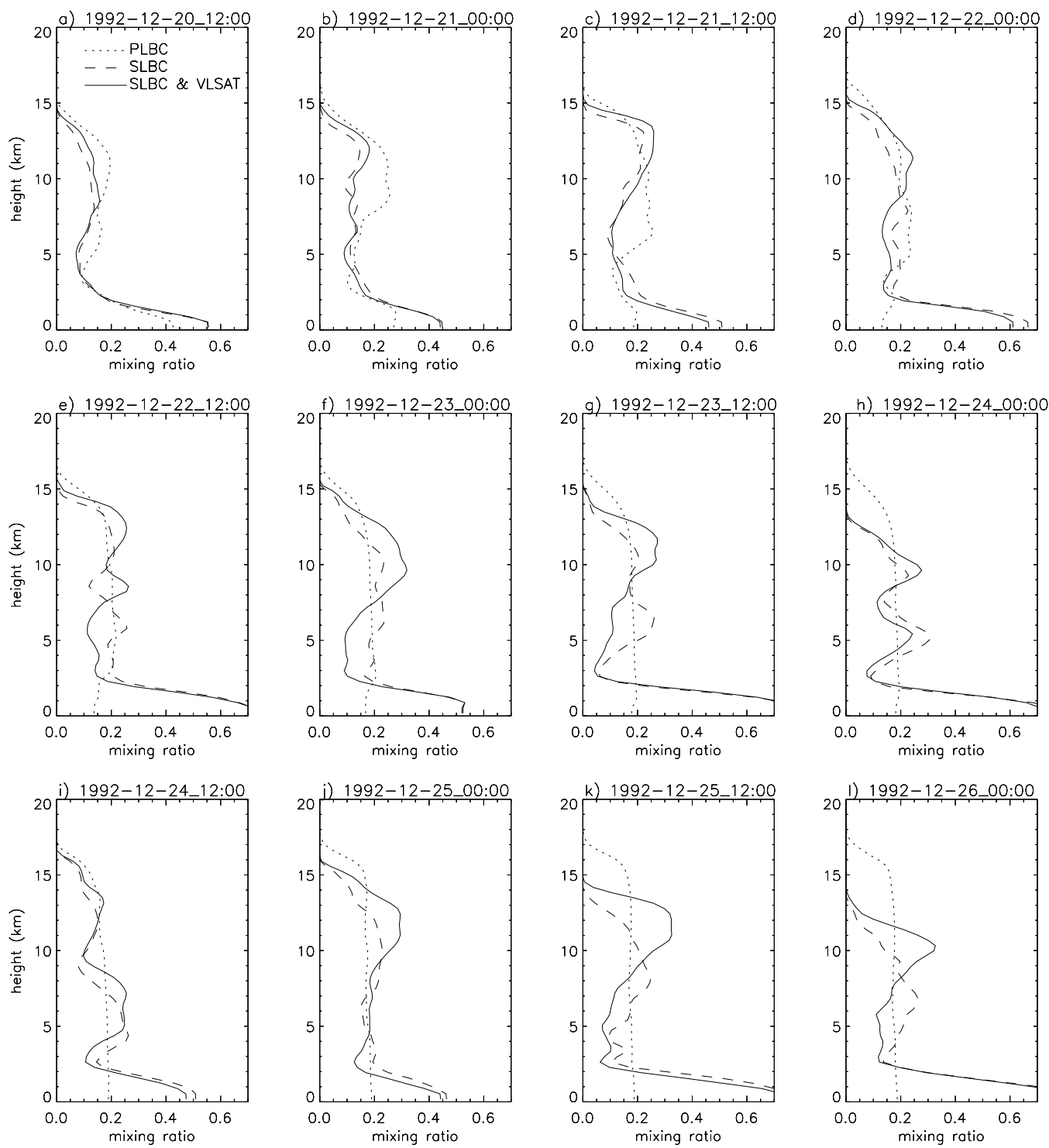

Fig. 7. Domain averaged vertical tracer profiles for tracer A every $12 \mathrm{~h}$ after the modelled convection sets in for a run with PLBCs (dotted line), a run in which the tracer concentrations were specified at the lateral domain boundary (dashed line) and a run with specified LBCs and VLSAT (solid line). Mixing ratio values were normalized to the maximum initial mixing ratio.

\subsubsection{Specified lateral boundary conditions}

During the first two days of the model run, the domain averaged mixing ratio for tracer B evolves similarly to its counterpart in the run with PLBCs when the VLSAT term is omitted (see Fig. 8b). When the VLSAT term is incorporated (see Fig. 8c) the mesoscale downward transport on 20 December is largely compensated. In Fig. 9 the mixing ratio contours of tracer B on 20 December 14:00 GMT are depicted for the three different sensitivity runs. In the run with PLBCs the mesoscale subsidence has caused the center of tracer mass to subside to nearly $3 \mathrm{~km}$ below its initial location. The strong effect of the mesoscale subsidence is also apparent for the SLBC run in Fig. 9b where the mixing ratio contours slope downwards from the inflow toward the outflow boundary. In the run in which the VLSAT term was included on the other hand a large fraction of the tracer mass has remained at its initial height. Between 21 and 22 December (see Fig. 8b again) when the westerly wind burst sets in, the total amount of tracer B in the domain decreases as a consequence of mesoscale subsidence, wind shear and transport across the lateral domain boundary. First the tracer is transported downwards because of the mesoscale subsidence to altitudes below $5 \mathrm{~km}$ where the average westerly wind is strong. From 


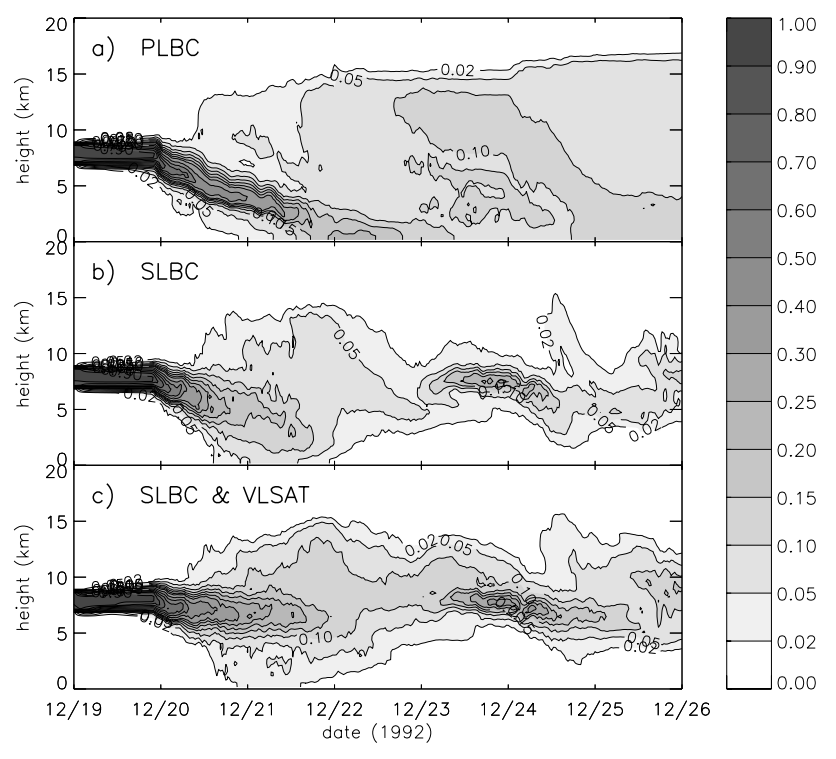

Fig. 8. As Fig. 6 for tracer B initialized at a constant concentration between 7000 and $8750 \mathrm{~m}$.

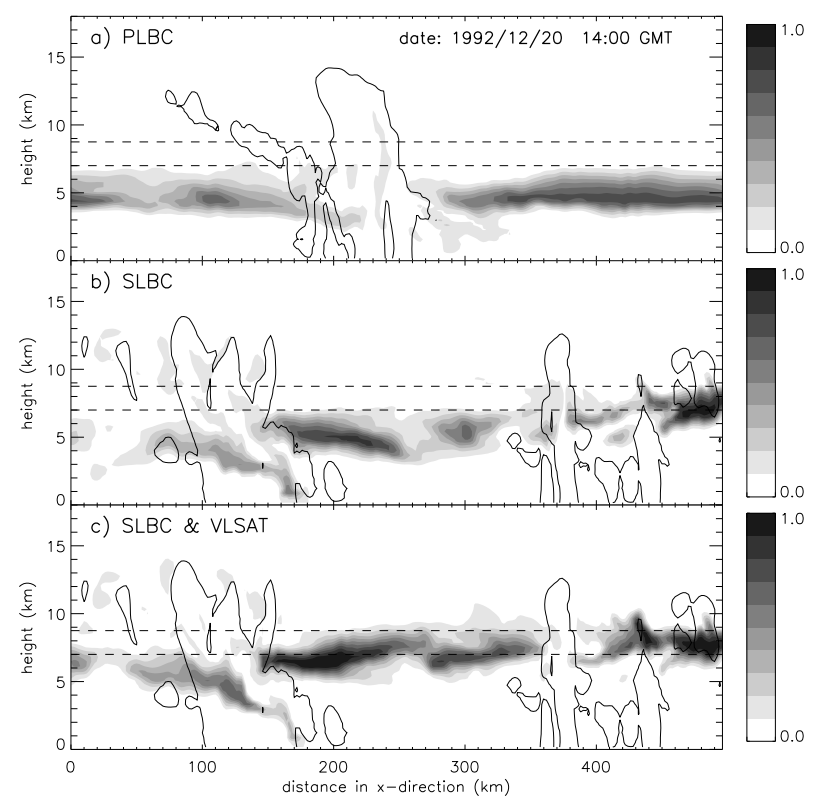

Fig. 9. Tracer B: X-Z contour plot of the normalized mixing ratio $\sim 16 \mathrm{~h}$ after the onset of modelled convection. The contour interval is 0.1 . Dashed lines indicate the initial tracer location, the solid line is the $0.1 \mathrm{~g} / \mathrm{kg}$ mixing ratio contour of the sum of all masses of hydrometeors in the ice and the liquid phase.

there it is rapidly transported eastwards to where it leaves the domain across its lateral boundary. For the tracer in the VLSAT run, in total more tracer mass remains inside the domain because the transport due to the mesoscale subsidence is largely compensated by the VLSAT. Around 24 December

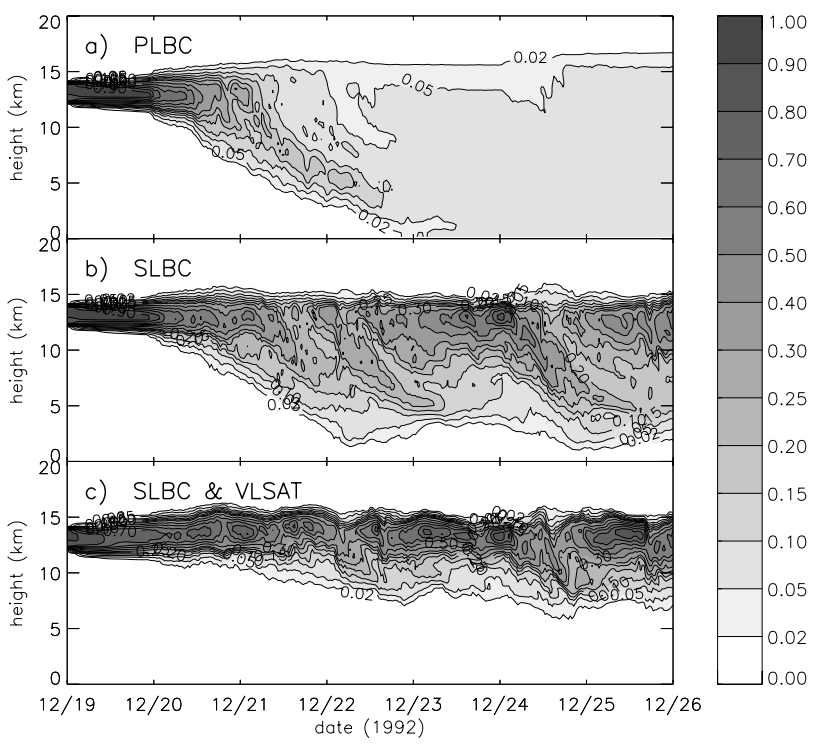

Fig. 10. As Fig. 6 for tracer $C$ initialized at a constant concentration between 12250 and $14000 \mathrm{~m}$.

the easterly wind at above $5 \mathrm{~km}$ height reaches a local maximum which transports "fresh" tracer into the domain. For a smaller domain (e.g. $248 \mathrm{~km}$, see Fig. 12a) the depletion of the tracer mass in the domain is weaker because during the time $\tau_{a d v}$ it takes the tracer to be advected across the entire length of the domain a smaller fraction of the tracer mass is transported downwards due to the mesoscale subsidence. For a larger model domain $(1000 \mathrm{~km})$ the depletion is also weaker (figure not shown) because $\tau_{a d v}$ is long enough so that not all of the tracer transported downward is transported out of the domain during the period before tracer mass is replenished by the increasing easterly wind.

\subsection{Tracer $\mathrm{C}$ in 2-D runs}

\subsubsection{Periodic lateral boundary conditions}

Tracer C (see Fig. 10a) was initialized in an upper tropospheric layer between 12250 and $14000 \mathrm{~m}$. About $12 \mathrm{~h}$ after the onset of the deep convection the first convection towers penetrate this layer and initiate downwards transport. The air inside the anvils carries a low tracer mixing ratio and replaces the air with high mixing ratios in the UT (which is pushed downwards along the lower edge of the anvils). Mesoscale subsidence acts to further transport tracer mass towards the Earth's surface. On 22 December a reduction in domain averaged mixing ratio located at $\sim 10 \mathrm{~km}$ altitude is calculated. The decrease in mixing ratio leading to this minimum is attributed to the transport of air with a low tracer mixing ratio from the LT to the UT. At the time of the subsequent increase of mixing ratio in the UT some air containing high tracer mixing ratio has reached the LT from where it is again transported upwards inside deep convective clouds. 


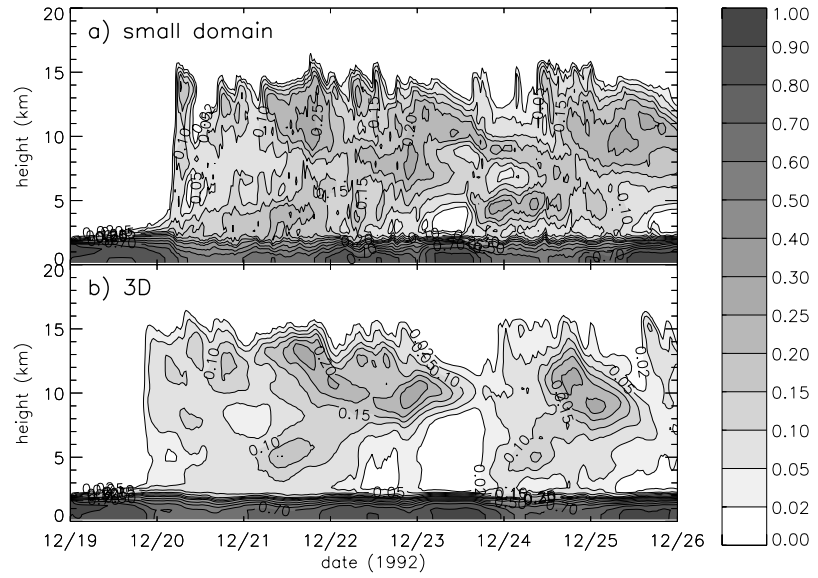

Fig. 11. As Fig. 6 but (a) for the $248 \mathrm{~km}$ long 2-D domain and (b) for the $248 \mathrm{~km} \times 248 \mathrm{~km}$ horizontal area 3-D domain.

Four days after the onset of deep convection the tracer is fairly well mixed throughout most of the model troposphere.

\subsubsection{Specified lateral boundary conditions}

As for the run with PLBCs tracer C is influenced by the penetration of deep convective towers and by mesoscale subsidence (see Fig. 10b and c). Because of the UT easterly winds some of the tracer mass advected downwards is replenished from outside the domain. If VLSAT is taken into account in the model (see Fig. 10c) considerably less tracer mass is transported to the LT than for the run with VLSAT switched off (Fig. 10b).

\subsection{Comparison 2-D vs. 3-D model runs}

Here, tracer transport results from a 3-D run with a $248 \mathrm{~km} \times 248 \mathrm{~km}$ horizontal domain size are compared to results from a 2-D run with a $248 \mathrm{~km}$ long domain. As described in Sect. 2.5 both runs were performed using SLBCs for the tracers and taking into account the VLSAT term. For tracer A, the results from both runs are depicted in Fig. 11. The time-height contours of the domain averaged tracer mixing ratio are smoother for the 3-D run than for the 2-D run, but the main features in Fig. 11a and b are similar, particularly during the first two days of active deep convection when the meridional wind component (see Fig. 2b) is small. On 22 December the southerly wind component in the UT starts increasing as well as the northerly wind component in the mid-troposphere. In the mid-troposhere tracer mass is advected out of the 3-D domain across the southern boundary on the 23rd (compare Fig. 11b). On 25 December an increasing southerly wind component in the mid-troposphere leads to an increase of tracer advection out of the domain across the northern boundary which is reflected in the $\mathrm{t}-\mathrm{z}$ contour plot for the 3-D run. For tracer B (see Fig. 12) one difference

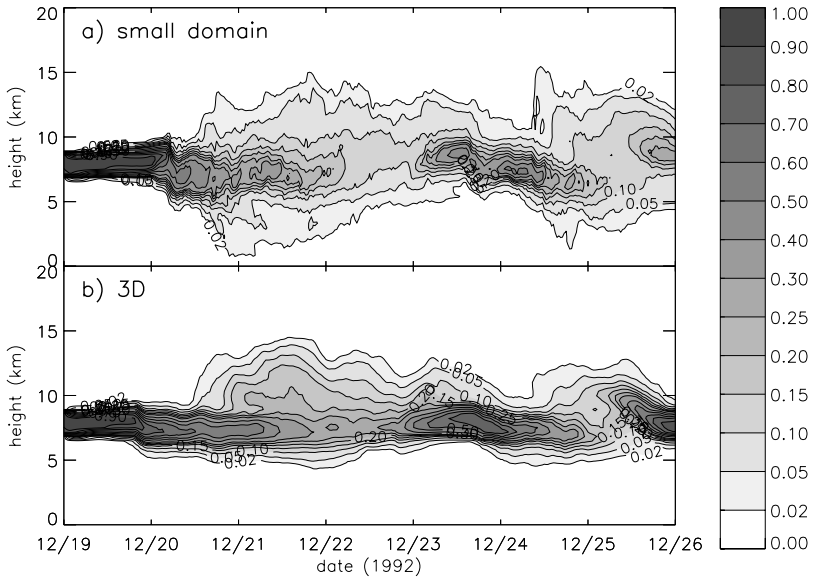

Fig. 12. As Fig. 11 for a tracer initialized at a constant concentration between 7000 and $8750 \mathrm{~m}$.

is the amount of tracer that remains in the lower troposphere. In the 3-D run, meridional tracer transport in the layers below the initial tracer mass location acts to advect tracer mass out of the domain. Cross-boundary advection in the meridional direction is also found to play an important role for the differences of the domain averaged mixing ratios of tracer $\mathrm{C}$ (see Fig. 13). Again subsiding tracer mass is advected out of the domain in the 3-D run due to the non-zero meridional wind component, while in the 2-D run advection in the meridional direction is not considered. Figure 14 shows the maximum cloud top heights in the domain for different runs. The cloud top height was defined as the first model level where the sum of all cloud meteor masses integrated downwards starting from the model top exceeds $5 \cdot 10^{-3} \mathrm{~kg} / \mathrm{m}^{2}$. Most notably, the maximum cloud top heights for the 3-D run are generally above those for the corresponding 2-D run. For the 500km domain 2-D runs, the maximum cloud top heights are largely independent of the boundary conditions applied. Differences in the downwards transport of tracer $\mathrm{C}$ are most likely caused by the application of VLSAT rather than by systematically different cloud top heights. Differences between 2-D and 3-D tracer transport model runs can also arise due to dynamical or microphysical reasons (e.g. Wang and Prinn, 2000). This study focuses mainly on the differences due to cross boundary transport. Cross boundary transport is believed to be the main reason for the differences between the results of the 2-D and the 3-D run presented here, but further research, including a 3-D simulation with PLBC, is needed in order to better differentiate between the different processes involved.

\section{Discussion}

Many trace gas compounds with tropospheric lifetimes between a few hours and a few weeks such as carbon monoxide or $\mathrm{NO}_{\mathrm{x}}$ (nitric oxide + nitrogen dioxide) have a source close 


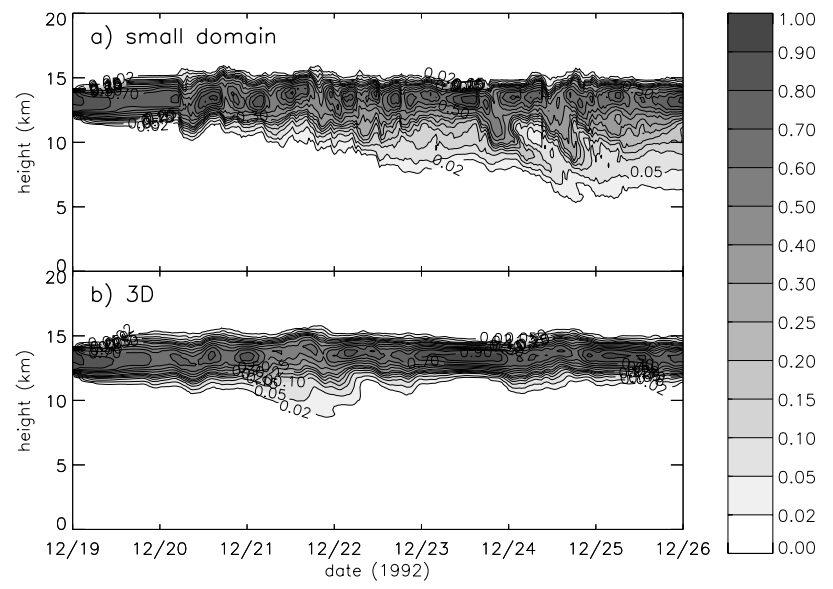

Fig. 13. As Fig. 11 for a tracer initialized at a constant concentration between 12250 and $14000 \mathrm{~m}$.

to the Earth's surface. Measured vertical mixing ratio profiles of these compounds in the vicinity of deep convection are often "C"- shaped, i.e. have a maximum in the LT and a second maximum in the UT (e.g. Dickerson et al., 1987; Gidel, 1983). On the other hand in post convective environments profiles of trace gases with a sink in the LT often have a minimum in the LT and a second minimum in the UT (e.g. Kley et al., 1997). Sometimes such a profile is referred to as "D"-shaped.

Tracer A can be considered an idealization of a moderately long lived, insoluble trace gas with a surface source. Its initial profile represents its idealized profile in an environment which has not been influenced by (either local or remote) deep convection recently. Figure 7 shows vertical profiles of model calculated tracer profiles for this tracer. During the first $36 \mathrm{~h}$ the tracer profile in the run with PLBCs still displays the typical "C"-shape caused by intermittent deep convective transport. After roughly three days the tracer is well mixed. If a constant wind speed of $5 \mathrm{~m} / \mathrm{s}$ is assumed, three days would correspond to a horizontal transport distance of $\sim 1300 \mathrm{~km}$ which is still smaller than the entire Pacific Warm Pool suggesting that moderately long lived tracers would be well mixed after having been advected at this wind speed straight across the entire Pacific Warm Pool. This could possibly also be expected as a result in a tracer CRM study with SLBCs and a sufficiently large domain size.

If chemistry transport CRM results are to be compared to measurements from field campaigns covering a limited area, a multi-day simulation with PLBCs will probably be of limited use since for moderately long lived tracers the effect of horizontal advection on these time scales is not negligible as demonstrated by the differences in Fig. $7 \mathrm{~b}$ to $\mathrm{f}$ and discussed previously. On the other hand, if LBCs would be specified from measurements, the method presented in this study could in principle be used for CRM simulations of

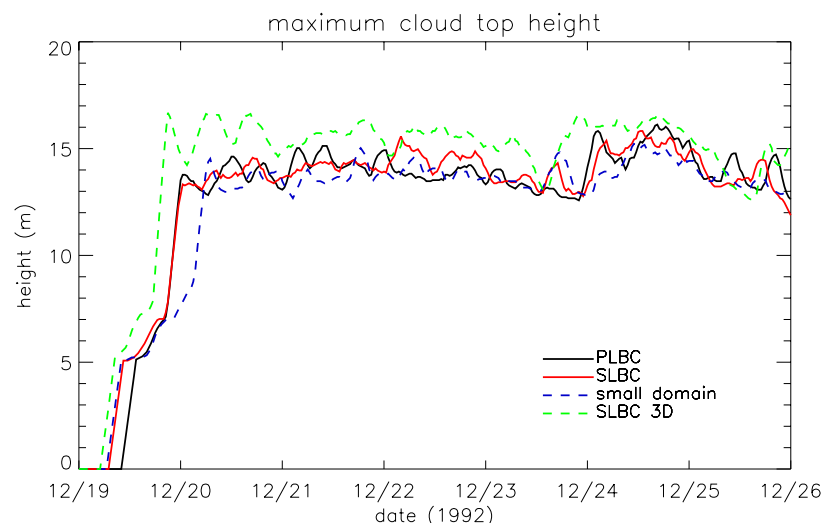

Fig. 14. Domain maximum cloud top heights. The sampling time was $30 \mathrm{~min}$ and a $3 \mathrm{~h}$ moving average is plotted. The cloud top height was defined as the first model level where the sum of all cloud meteor masses integrated downwards starting from the model top exceeds $5 \cdot 10^{-3} \mathrm{~kg} / \mathrm{m}^{2}$.

trace gas dispersion due to deep convective clouds. However, in order to obtain the necessary input data for such a simulation, a comprehensive field campaign of the size of the TOGA-COARE campaign encompassing both meteorological and trace gas measurements would be necessary. No such campaign has been planned. Nevertheless, input data from different sources, including both field campaigns and results from global chemistry transport models (GCTMs) could be used to specify the necessary boundary conditions for CRMs with the setup proposed here.

Here the transport of idealized tracers was studied and the boundary conditions were kept fixed. For more realistic studies, time-dependent boundary values for trace gases can be prescribed to the extent they are available.

Another potentially useful application for the setup described in this study could be the comparison between tracer transport results from CRMs and parameterizations used in global models. In global chemistry transport models convective transport constitutes a major source of uncertainty since it is highly sensitive to the convective parameterization applied (Mahowald et al., 1995) and even to the treatment of transport based on the mass fluxes provided by individual schemes (Lawrence and Rasch, submitted, 2004) ${ }^{1}$. Cloud-resolving models (CRMs) in combination with single column models (SCMs) could perhaps help to better evaluate these parameterizations and thus reduce this uncertainty. For TOGA-COARE a comparison between different single column models including tracer transport was presented by Rasch et al. (2003). A similar framework as the one presented here could be used in multi-day single column model

\footnotetext{
${ }^{1}$ Lawrence, M. G. and Rasch, P. J.: Tracer transport in deep convective updrafts: plume ensemble versus bulk formulations, J. Atmos. Sci., submitted, 2004.
} 
(SCM) studies. Comparisons between SCMs and CRMs would draw substantial benefits from the method presented here. In current global models convective tracer transport is commonly parameterized using the assumption that the upwards advection of air mass inside the convective clouds is balanced by the mesoscale subsidence in the same vertical model column. The tracer transport due to large-scale ascent is calculated separately using the so-called operator splitting technique. This method used in global models is analogous to the method used here, in this CRM study.

The setup with specified LBCs for water vapour allows for larger differences between modelled and observed surface precipitation than the setup with PLBCs and thus could possibly be useful for evaluating different microphysics schemes.

A drawback of specifying LBCs for tracers and retaining PLBCs for the air density is that the advection of tracer mass at a given height level due to the domain averaged horizontal air mass convergence or divergence into or out of the domain is neglected. The domain averaged mass flux divergence (advection) of the tracers is due to the difference in influx and outflux across the domain boundaries in this study. While the tracer mass flux at the inflow boundary depends on the specified tracer concentration and the wind, the mass flux at the outflow boundary is influenced by the modelled tracer transport inside the domain. In small domains containing a single convective system and under conditions of weak horizontal average winds, the domain averaged mass flux divergence due to large scale wind convergence and divergence into and out of the model domain is likely to become important.

The results of runs using SLBCs for tracers are domain size dependent, although in this study the differences between the runs with $500 \mathrm{~km}$ domain size (see Figs. $6 \mathrm{c}$ to 10c) and $248 \mathrm{~km}$ domain size (see Figs. 11c to 13c) are often small. For either much smaller or much larger domains, a stronger domain size dependence may be expected. This domain size dependence should not be considered a drawback of the method but is an advantage in cases in which model results from future multi-day chemistry transport CRM studies are to be compared to measurements.

In the case study presented here, the VLSAT often has a strong effect on the domain averaged vertical profiles, particularly when $\tau_{a d v}$ is long (e.g. Fig. 7e-g, k, and l) and should not be neglected. In CRM studies of reactive tracer transport the over-estimation of downwards trace gas transport, as seen in tracers B and C, could otherwise for example lead to unrealistically high chemical $\mathrm{NO}_{\mathrm{x}}$ sources in the mid-troposphere due to the thermal decomposition of subsiding PAN (peroxy acetyl nitrate) or pernitric acid. The spurious downward transport of tracers when the VLSAT is neglected can easily be mis-interpreted as the effect of mid-level detrainment.

The results for the PLBC runs in this study are similar to the results presented by $\mathrm{Lu}$ et al. (2000), i.e., in the model runs with PLBC, the tracers are transported from the midand upper troposphere to the LT with a timescale of approx- imately one day. Figures 15 and 16 of Lu et al. (2000) can be compared to Figs. 6a to 10a for the first days of modelled deep convection. Lu et al. (2000) chose to re-initialize their model every $60 \mathrm{~h}$ and used a domain length of $512 \mathrm{~km}$. Using sensitivity runs for a $500 \mathrm{~km}$ domain, it was demonstrated in this study that the modelled tracer transport is highly sensitive to the choice of LBC, even on timescales of a few days. Furthermore it was shown that including VLSAT changes some main characteristics of the modeled tracer transport. In multi-day CRM studies of tracer transport in regions with large scale vertical ascent, such as the Pacific Warm Pool, the VLSAT term has to be considered. Since current CRMs do not allow the exchange of airmass across the lateral domain boundaries, the VLSAT must be considered as well as the corresponding terms for $q$ and $\theta$.

\section{Conclusions}

A setup designed for modelling multi-day tracer transport in a current CRM was described and the transport of idealized tracers was studied. The results obtained with this setup were compared to results obtained with a setup previously used in a similar case study ( $\mathrm{Lu}$ et al., 2000). In the new setup, specifying LBCs for tracers allows the effects of horizontal tracer advection into and out of the model domain to be considered. Less than $24 \mathrm{~h}$ after the onset of deep convection in the model, the results for the different setups started to differ significantly. In general, if no large scale advection terms for tracers are prescribed from observations, PLBCs should not be used for model studies of tracer transport if the simulated time $t_{\text {sim }}$ is longer than the advective time scale $\tau_{a d v}=L / \bar{v}_{\max }$ and $\tau_{l}>\tau_{a d v}$, where $\tau_{l}$ is the tracer's chemical life time. For studies of reactive, or soluble tracer transport, prescribing horizontally homogeneous horizontal tracer LSA terms from observations could in some cases be problematic because large horizontal gradients can form in the simulations. This would have to be examined in future studies.

Furthermore it was demonstrated that including a VLSAT term, which was not included in previous studies of tracer transport, partially compensates the net-downward transport of tracers from the middle and upper troposphere due to the mesoscale subsidence induced by deep convection. This term should be considered in future multi-day limited area CRM studies of tracer transport.

For the first time, tracer transport results from a multiday 3-D model run were presented and compared to results from a 2-D run. Differences between the 2-D and 3-D run were mainly attributed to an increase in horizontal advection across the lateral domain boundaries due to the meridional wind component in the 3-D model runs which was not considered in the 2-D simulations.

The model setup used in this study facilitates comparisons with either trace gas measurements from multi-day field campaigns or with results from single column cloud models, thus 
possibly providing one means to help evaluate deep convective transport parameterizations used in global models.

A drawback of the new setup arises from retaining PLBCs for air density. In the future a model setup allowing the convergence or divergence of airmass into or out of the model domain at a given height could be considered for trace gas transport studies. One possibility would be to try to develop a method using nested models in combination with e.g. a gridded input dataset based on meteorological measurements from the TOGA-COARE campaign. In contrast to conventional CRMs, the WRF model was designed as a regional model which is capable of operating at high resolutions. WRF allows for multiple nesting, and air quality models based on WRF are currently being developed at different institutions including NCAR.

The setup as described here will be used to investigate the effect of a cumulus ensemble on the dispersion of reactive trace gases such as ozone. For this purpose a tropospheric chemistry mechanism based on the global Model of Atmospheric Transport and Chemistry - Max Planck Institute for Chemistry (MATCH-MPIC, Lawrence et al., 1999; von Kuhlmann et al., 2003, and references therein) has been implemented into the CRM. Furthermore, a more comprehensive study about the sensitivity of the tracer transport results to different model configurations such as different resolutions, microphysics schemes and domain sizes is planned.

Acknowledgements. We appreciate valuable discussions with several colleagues, especially R. von Kuhlmann and B. Bonn, and valuable comments by $\mathrm{C}$. Wang and two other anonymous referees. This research was supported by funding from the German Ministry of Education and Research (BMBF), project 07-ATC-02. Results from this study will be submitted in a Ph.D. thesis at the University of Mainz, Department for Atmospheric Physics.

Edited by: U. Lohmann

\section{References}

Andronache, C., Donner, L. J., Seman, C. J. Ramaswamy, V., and Hemler, R. S., : Sulfur dioxide in remote oceanic air: Atmospheric sulfur and deep convective clouds in tropical Pacific: A model study, J. Geophys. Res., 104, 4005-4024, 1999.

Chatfield, R. B. and Crutzen, P. J.: Sulfur dioxide in remote oceanic air: Cloud transport of reactive precursors, J. Geophys. Res., 89, 7111-7132, 1984.

Chou, M.-D., Suarez, M. J., Ho, C.-H., Yan, M. M.-H., and Lee, K.-T.: Parameterizations for cloud overlapping and shortwave single-scattering properties for use in general circulation and cloud ensemble models, J. Climate, 11, 202-214, 1998.

Ciesielski, P. E., Johnson, R. H., Haertel, P. T., and Wang, J.: Corrected TOGA COARE sounding humidity data: Impact on diagnosed properties of convection and climate over the warm pool, J. Climate, 16, 2370-2384, 2003.

Dickerson, R. R., Huffman, G. J., Luke, W. T., Nunnermacker, L. J., Pickering, K. E., Leslie, A. C. D., Lindsey, C. G., Slinn, W. G. N.,
Kelly, T. J., Daum, P. H., Delaney, A. C., Greenberg, J. P., Zimmerman, P. R., Boatman, J. F., Ray, J. D., and Stedman, D. H.: Thunderstorms: An important mechanism in the transport of air pollutants, Science, 235, 460-465, 1987.

Ekman, A. M. L., Wang, C., Ström, J., and J. Wilson: Explicit simulation of aerosol physics in a cloud-resolving model, Atmos. Chem. Phys., 4, 773-791, 2004,

SRef-ID: 1680-7324/acp/2004-4-773.

GCSS Science Team: The GEWEX Cloud System Study (GCSS), Bull. Am. Met. Soc., 74, 387-399, 1993.

Gidel, L. T.: Cumulus cloud transport of transient tracers, J. Geophys. Res., 88, 6587-6599, 1983.

Gregory, D. and Guichard, F.: Aspects of the parameterization of organized convection: Contrasting cloud resolving model and single-column model realizations, Q. J. R. Meteorol. Soc., 128, 625-646, 2001.

Johnson, D. E., Tao, W.-K., Simpson, J., and Sui, C.-H.: A study of the response of deep tropical clouds to large-scale thermodynamic forcings, Part I: Modeling strategies and simulations of TOGA COARE convective systems, J. Atmos. Sci., 59, 34923518, 2002.

Kley, D., Smit, H. G. J., Vömel, H., Grassl, H., Ramanathan, V., Crutzen, P. J., Williams, S., Meyerwerk, J., and Oltmans, S. J.: Tropospheric water-vapour and ozone cross-sections in a zonal plane over the central equatorial Pacific Ocean, Q. J. R. Meteorol. Soc., 123, 2009-2040, 1997.

Krueger, S. K. and Lazarus, S. M.: Intercomparison of multi-day simulations of convection during TOGA COARE with several cloud-resolving and single-column models, in Preprints, 23rd Conf. on Hurricanes and Tropical Meteorology, Amer. Meteor. Soc., Dallas, TX, 1999.

Krueger, S. K., Fu, Q., Liou, K. N., and Chin, H.-N. S.: Improvements of an ice-phase microphysics parameterization for use in numerical simulations of tropical convection, J. Appl. Met., 34, 281-287, 1995.

Lawrence, M. G., Crutzen, P. J., Rasch, P. J., Eaton, B. E., and Mahowald, N. M.: A model for studies of tropospheric photochemistry: Description, global distributions, and evaluation, J. Geophys. Res., 104, 26 245-26 277, 1999.

Lawrence, M. G., von Kuhlmann, R., Salzmann, M., and Rasch, P. J.: The balance of effects of deep convective mixing on tropospheric ozone, Geophys. Res. Lett., 30, art. no. 1940, 2003.

Lelieveld, J. and Crutzen, P. J.: Role of deep cloud convection in the ozone budget of the troposphere, Science, 264, 1759-1761, 1994.

Lin, Y.-L., Farley, R. D., and Orville, H. D.: Bulk parameterization of the snow field in a cloud model, J. Climate Appl. Meteor., 2, 1065-1092, 1983.

Lord, S. J., Willoughby, H. E., and Piotrowicz, J. M.: Role of a parameterized ice-phase microphysics in an axisymmetric, nonhydrostatic tropical cyclone model, J. Atmos. Sci., 42, 2836-2848, 1984.

Lu, R., Lin, C., Turco, R., and Arakawa, A.: Cumulus transport of chemical tracers, 1. Cloud-resolving model simulations, J. Geophys. Res., 105, 10 001-10 221, 2000.

Mahowald, N. M., Rasch, P. J., and Prinn, R. G.: Cumulus parameterizations in chemical transport models, J. Geophys. Res., 100, 26 173-26 189, 1995. 
Mari, C., Jacob, D. J., and Bechtold, P.: Transport and scavenging of soluble gases in a deep convective cloud, J. Geophys. Res., 105, 22 255-22 267, 2000.

Mlawer, E. J., Taubman, S. J., Brown, P. D., Iacono, M. J., and Clough, S. A.: Radiative transfer for inhomogeneous atmosphere: RRTM a validated correlated-k model for the longwave, J. Geophys. Res., 102, 16663-16 682, 1997.

Pickering, K. E., Thompson, A. M., Dickerson, R. R., Luke, W. T., McNamara, D. P., Greenberg, J. P., and Zimmerman, P. R.: Model calculations of tropospheric ozone production potential following observed convective events, J. Geophys. Res., 95, 14 049-14 062, 1990.

Pickering, K. E., Thompson, A. M., Kim, H., DeCaria, A. J., Pfister, L., Kucsera, T. L., Witte, J. C., Avery, M. A., Blake, D. R., Crawford, J. H., Heikes, B. G., Sachse, G. W., Sandholm, S. T., and Talbot, R. W.: Trace gas transport and scavenging in PEMTropics B South Pacific Convergence Zone convection, J. Geophys. Res., 106, 32 591-32 602, 2001

Rasch, P., Zurovac-Jevtic, D., Emanuel, K., and Lawrence, M.: Consistent representation of convective processes for chemistry and climate models, Geophys. Res. Abstr., 5, 12 440, 2003.

Scala, J. R., Garstang, M., Tao, W.-K., Pickering, K. E., Thompson, A. M., Simpson, J., Kirchhoff, V. W. J. H., Browell, E. V., Sachse, G. W., Torres, A. L., Gregory, G. L., Rasmussen, R., and Khalil, M. A. K.: Cloud draft structures and trace gas transport, J. Geophys. Res., 95, 17 015-17 030, 1990.

Skamarock, W. C., Klemp, J. B., and Dudhia, J.: Prototypes for the WRF (Weather Research and Forecasting) model, in Preprints, Ninth Conf. Mesoscale Processes, pp. J11-J15, Amer. Meteor. Soc., Fort Lauderdale, FL, 2001.

Skamarock, W. C., Powers, J. G., Barth, M., Dye, J. E., Matejka, T., Bartels, D., Baumann, K., Stith, J., Parrish, D. D., and Hubler, G.: Numerical simulations of the July 10 StratosphericTropospheric Experiment: Radiation, Aerosols, and Ozone/Deep Convection Experiment convective system: Kinematics and transport, J. Geophys. Res., 105, 19 973-19990, 2000.

Soong, S.-T. and Ogura, Y.: Response of tradewind cumuli to largescale processes, J. Atmos. Sci., 37, 2035-2050, 1980.
Su, H., Chen, S. S., and Bretherton, C. S.: Three-dimensional weeklong simulations of TOGA COARE convective systems using the MM5 mesoscale model, J. Atmos. Sci., 56, 2326-2344, 1999.

Takemi, T. and Rotunno, R.: The effects of subgrid model mixing and numerical filtering in simulations of mesoscale cloud systems, Mon. Weather Rev., 131, 2085-2191, 2003.

von Kuhlmann, R., Lawrence, M. G., Crutzen, P. J., and Rasch, P. J.: A model for studies of tropospheric ozone and nonmethane hydrocarbons: Model description and ozone results, J. Geophys. Res., 108, doi:10.1029/2002JD002893, 2003.

Walcek, C. J.: Minor flux adjustment near mixing ratio extremes for simplified yet highly accurate monotonic calculation of tracer advection, J. Geophys. Res., 105, 9335-9348, 2000.

Wang, C. and Chang, J. S.: A three-dimensional numerical model of cloud dynamics, microphysics, and chemistry: 3. Redistribution of pollutants, J. Geophys. Res., 98, 16 787-16 798, 1993.

Wang, C. and Prinn, R. G.: On the roles of deep convective clouds in tropospheric chemistry, J. Geophys. Res., 105, 22 269-22 297, 2000.

Webster, P. J. and Lukas, R.: TOGA COARE: The Coupled OceanAtmosphere Response Experiment, Bull. Am. Met. Soc., 73, 1377-1416, 1992.

Wicker, L. J. and Skamarock, W. C.: Time-splitting methods for elastic models using forward time schemes, Mon. Weather Rev., 130, 2088-2097, 2002.

Wu, X., Grabowski, W. W., and Moncrieff, M. W.: Long-term behavior of cloud systems in TOGA COARE and their interactions with radiative and surface processes. Part I: Two-dimensional modeling study, J. Atmos. Sci., 55, 2693-2714, 1998.

$\mathrm{Xu}, \mathrm{K} . \mathrm{-M}$. and Krueger, S. K.: Evaluation of cloudiness parameterizations using a cumulus ensemble model, Mon. Weather Rev., 119, 342-367, 1991.

$\mathrm{Xu}, \mathrm{K} . \mathrm{-M}$. and Randall, D.: Explicit simulation of cumulus ensembles with GATE phase III data: Comparison with observations, J. Atmos. Sci., 53, 3710-3736, 1996.

$\mathrm{Xu}$, K.-M., Arakawa, A., and Krueger, S. K.: The macroscopic behaviour of cumulus ensembles simulated by a cumulus ensemble model, J. Atmos. Sci., 49, 2402-2420, 1992. 